Sādhanā Vol. 38, Part 4, August 2013, pp. 723-741. (C) Indian Academy of Sciences

\title{
Application of digital image correlation method for analysing crack variation of reinforced concrete beams
}

\author{
MING-HSIANG SHIH ${ }^{1}$ and WEN-PEI SUNG ${ }^{2, *}$ \\ ${ }^{1}$ Department of Civil Engineering, National Chi Nan University, \\ Puli, Nantou 545, Taiwan \\ ${ }^{2}$ Department of Landscape Architecture, National Chin-Yi University of Technology, \\ Taichung 41111, Taiwan \\ e-mail:wps@ncut.edu.tw; drwpsung@yahoo.com.tw
}

MS received 1 October 2012; revised 23 February 2013; accepted 23 March 2013

\begin{abstract}
The Digital Image Correlation (DIC) method is a fast-growing emerging technology that provides a low-cost method for measuring the strain of an object. In this study, the feasibility of using this method to observe cracks developed in reinforced concrete beams will be explored so that a practical application can be proposed. The DIC method has been applied for analysing the field of surface displacement and strain; it is not applicable for measuring non-continuous field of displacement. However, if a singular point (i.e., crack points) can be considered as the area of concentrated strain by imitating the treatment of micro-cracks using the finite element method, the region of concentrated strain field based on analyses of digital images can be applied for determining the locations of cracks. Laboratory results show that cracks developed in reinforced cement beams can be observed with a good precision using the von Mises strain field, and that smaller grids lead to clearer crack images. In addition to identifying visible cracks, the DIC image analysis will enable researchers to identify minute cracks that are not visible to naked eyes. Additionally, the DIC method has more accuracy and precision than visual observation for analysing crack loadings so that earlier warnings can be realized before cracks develop in the specimen.
\end{abstract}

Keywords. Digital image correlation (DIC); R.C. beam; product quality; crack development.

\section{Introduction}

Strain analysis is an important topic in civil and mechanical engineering concerning the phenomenon of stress concentration especially in heterotrophic materials. The traditional technology for measuring strains consists of two methods: (i) using a strain meter to measure the average strain of a section at the target location, or using a displacement meter to measure the relative

*For correspondence 
movement of two points, and then converting the measurement into average strain, and (ii) making grids on the specimen before deformation, and measuring the displacements of various grids after specimen deformation to calculate the strain field of each grid. Method (i) has the disadvantage of not being capable of obtaining the strain for the whole field, whereas method (ii) is tedious and time-consuming. Therefore, traditional methods do not satisfy our needs to perform analyses of strain distribution.

Additionally, the traditional strain measurement relies on direct contact between the instrument and the specimen surface to obtain the quantity of strain or displacement that is sometimes impossible to carry out in certain unfavourable conditions. For example, the instrument cannot be brought close to distance bridges, steel structures subject to high temperature and pressure, and objects in radioactive environment, among many others. A more serious problem of using the conventional measuring device is that the strain meter often separates from the specimen when the latter is undergoing great deformation to seriously interfere with the strain measurement during the later stage of the experimental period. Our research team has developed a DIC-based non-contact method to overcome these problems for measuring deformation. Developing the DIC method into a rapid, cost-effective with high precision technology is made possible by rapid advances in digital photography and computer technology in recent years. In addition to its application in large-scale civil engineering projects, the DIC method can be combined with various other measuring techniques such as radiography for observing external deformation and interior cracking of an object simultaneously so that the observed material deformation can be clearly related to internal failure.

When subject to gravitational pressure, the reinforced concrete structure will easily develop cracks due to thermal expansion and contraction, and uneven foundation subsidence. This causes water and moisture to penetrate the concrete leading to serious rust of the reinforcing steel bars to weaken the structure. Hence, monitoring cracks developed in reinforced concrete structure is an important link for diagnosing structural health. Chen \& Liu (2004) proposed the acoustic emission (AE) method by measuring the brittle failure of reinforced concrete beam subject to three-point forces. Yehia (2009) to apply fracture mechanics for simulating the flexural strength of reinforced concrete beam based on experimental results; but this method is incapable of precisely describing variations of strain caused by stress. Zhang \& Liu (2003) applied the three-point bending test to evaluate the influence of coarse aggregate and cementitious matrix strength on the stress-crack width relationship, tensile strength and fracture energy of concrete. However, they failed to prove the correlation between crack or failure and loading. Ozcan et al (2009) used the four-point test and the finite element method to investigate the correlation between failure load and displacement. Swartz \& Taha (1991) utilized finite element codes, with linear elastic fracture mechanics and nonlinear fracture mechanics to describe the crack propagation and fracture behaviour of plain concrete beams with Iosipscu-type geometry and loading in four-point bending with and without the presence of axial compression. Ru et al (2011) applied extended finite element method (XFEM) to analyse the location of the crack imposes on the crack propagation direction of plain concrete beam subjected to three-point bending test. Ray \& Kishen (2012) proposed the fundamental principles of dimensional analysis and self-similarity to overcome the empirical nature of the analytical models. This model is applied to compare with the experimental test of three-point bend beams and compact tension specimens. The results display the validness of this model. All the test methods of above-mentioned studies were followed by the traditional experimental method. Non-DIC methods have been proposed in literature for observing cracks in reinforced concrete. Therefore, the DIC method (Chu et al 1985; Bruck et al 1989; Sutton et al 1991; Lu \& Cary 2000) combines with the deformation theory 
by using optical measurement to obtain digital images of the specimen before and after deformation and then analysing the images to determine the relative displacement field so that the strain distribution on the deformed surface of the specimen can be revealed. In recent years, many researchers (Vellinga \& Onraet 2000; Vendroux \& Knauss 1998) applied technology that combines DIC method and micrographic observation to perform micro-range strains. Laboratory results show that the DIC method is feasible for observing and analysing nano-scale deformation. Dost et al (2003) proposed the use of DIC method to observe minute cracks and microscope to measure the dimensions in nano-scale, and the results confirmed the obvious discrete movements for either side of the crack.

Hence, in this research, the feasibility of utilizing the DIC method for observing the development of cracks in reinforced concrete beams under loading is studied. The research further covers applying the DIC method as quantitative analyses for detecting early occurrence and progress of cracks. The correlations among various grey values of digital images are analysed for obtaining the distribution of displacement and strain fields surrounding the crack in order to investigate the relationship between strain and stress.

\section{Theory of the digital image correlation method}

The 'structural speckle' (Shih et al 2008) will be established on the specimen surface first to make non-uniform distribution of grey scales. This grey scale distribution characteristic will be used in the DIC method to compare the deformed and un-deformed images in order to obtain relative positions. These displacement vectors of various image points are calculated to infer the normal strains, shear strain and von Mises strain field. The material testing result of RC beam shows when this kind material is going to be loaded past the yield strength of the material, plastic deformation will occur. Therefore, von Mises material model is proposed to analyse the mechanics behaviours of RC beam in this research.

\subsection{Two-dimensional digital image correlation method}

DIC is widely applied in the field of image identification technique by comparing the local correlation of two images; the relationship between deformed and un-deformed images can be identified. As shown in figure 1, the central point prior to deformation is point P; it is changed to point $\mathrm{P}^{*}$ after deformation. The functional relationship is expressed as (Shih et al 2008)

$$
\begin{aligned}
& x^{*}=x+u(x, y) \\
& y^{*}=y+v(x, y) .
\end{aligned}
$$

For un-deformed images, finite element method (FEM) is used to divide the images into several sub-images as shown in figure 2 . Assuming the un-deformed sub-image is $A$, and the deformed sub-image is $B$, the correlation coefficient (Equation 2) (Chu et al 1985) is used to define the relationship between sub-images $A$ and $B$. When sub-image $\mathrm{B}$ is exactly the same as sub-image A after deformation, the correlation coefficient will be equal to 1 .

$$
\mathrm{COF}=\frac{\Sigma g_{i j} \widetilde{g}_{\overline{i j}}}{\sqrt{\Sigma g_{i j}^{2} \cdot \Sigma \widetilde{g}_{\overline{i j}}^{2}}},
$$




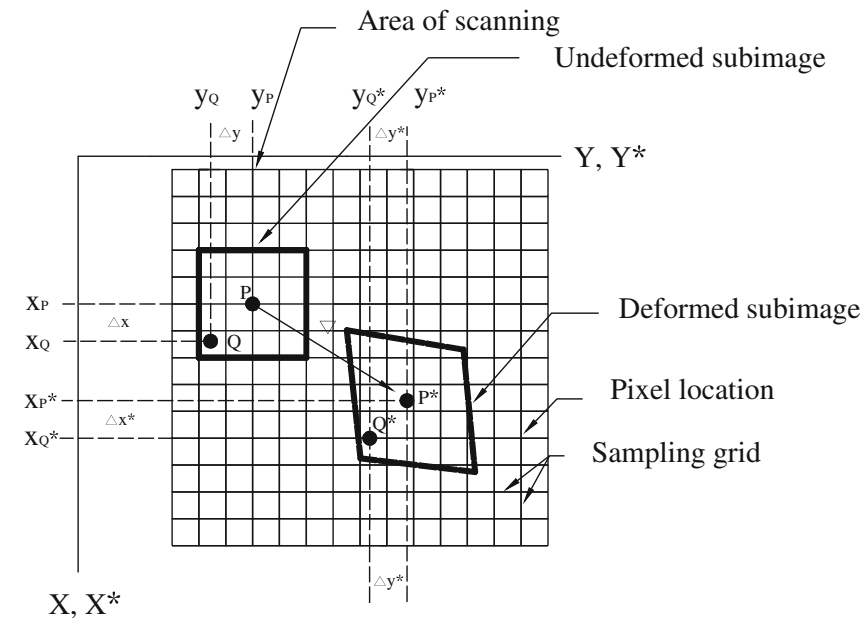

Figure 1. Schematic drawing of relative location of subimages of deformed and un-deformed images on surface (Chu et al 1985).

where, $g_{i j}$ and $\widetilde{g}_{\overline{i j}}$ are grey scale of image A on coordinate $(i, j)$ and image B on coordinate $(\bar{i}, \bar{j})$, respectively; coordinate $(\bar{i}, \bar{j})$ of image B corresponds to coordinate $(i, j)$ of image A.

\subsection{Calculation of strain field}

Green-Lagrange's tensor $E$ is defined as

$$
E=\frac{1}{2}\left[F^{T} \otimes F-1\right],
$$

where, $F$ is gradient tensor of displacement field, and $I$ is unit matrix.

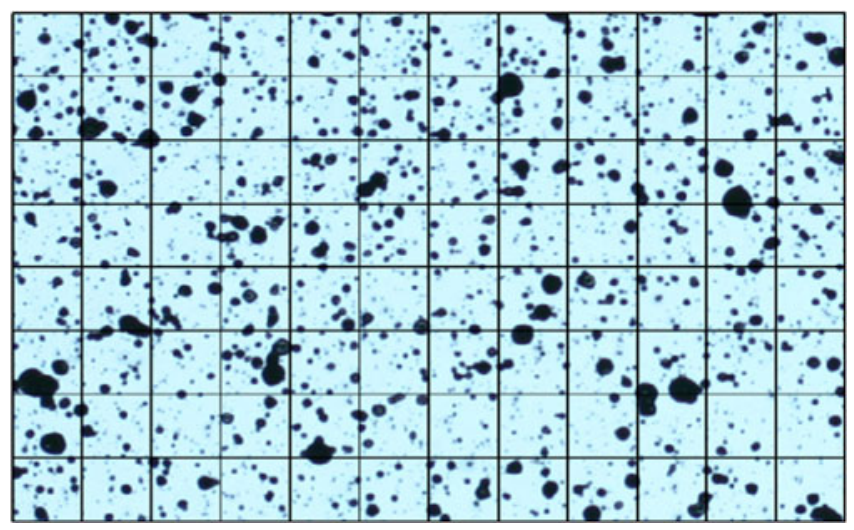

Figure 2. Schematic drawing of sub-images (grids) on surface (Shih et al 2008). 
Tensor $E$ is rewritten into the function of displacement field as follows: (Chu et al 1985)

$$
E_{i j}=\frac{1}{2}\left(u_{i, j}+u_{j, i}\right)+\frac{1}{2} u_{k, i} u_{k, j},
$$

where, $i, j, k \in(x, y)$, and $u_{i, j}=\partial u_{i} / \partial j$.

Strain is computed using the following equations

$$
\begin{gathered}
\varepsilon_{x x}=\frac{\partial u_{x}}{\partial x}+\frac{1}{2}\left[\left(\frac{\partial u_{x}}{\partial x}\right)^{2}+\left(\frac{\partial u_{y}}{\partial x}\right)^{2}\right] \\
\varepsilon_{y y}=\frac{\partial u_{y}}{\partial y}+\frac{1}{2}\left[\left(\frac{\partial u_{x}}{\partial y}\right)^{2}+\left(\frac{\partial u_{y}}{\partial y}\right)^{2}\right] \\
\varepsilon_{x y}=\frac{1}{2}\left(\frac{\partial u_{x}}{\partial y}+\frac{\partial u_{y}}{\partial x}\right)+\frac{1}{2}\left[\frac{\partial u_{x}}{\partial x} \frac{\partial u_{x}}{\partial y}+\frac{\partial u_{y}}{\partial x} \frac{\partial u_{y}}{\partial y}\right] \\
\varepsilon_{v M}=\frac{\sqrt{\left.2\left(\varepsilon_{1}-\varepsilon_{3}\right)^{2}+\varepsilon_{1}^{2}+\varepsilon_{3}^{2}\right)}}{3}
\end{gathered}
$$

where, $\varepsilon_{v M}$ is the von Mises strain (Mendelson 1983), $\varepsilon_{1}$ and $\varepsilon_{3}$ are the major and minor principle stresses, respectively.

\subsection{Measuring crack width and dislocation length}

Discontinuity of the specimen surface displacement field on the specimen surface obtained using DIC method is used to further analyse the relative lateral displacement of either side of the crack, and the crack direction so that the crack width and slip length are calculated as illustrated in the following sections:

Figure 3 shows the variation of specimen surface before and after cracking. The angle measured from the horizontal line to the future cracking line is $\theta$. Points $P$ and $Q$ are two points before crack occurs on either side of the cracking line, and the line connecting $P$ and $Q$ is perpendicular to the cracking line. The occurrence of a crack leads to relative motion between
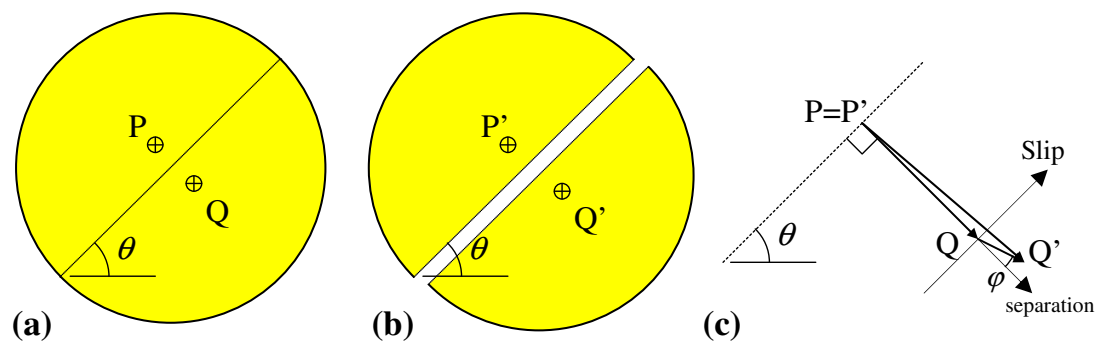

Figure 3. Changes of the relative positions after cracking occurs. (a) before cracking, (b) after cracking, (c) relative displacement. 
Table 1. Extreme cracking behaviour.

\begin{tabular}{lccl}
\hline Angle $\phi$ & Separation $w_{c}$ & Dislocation $\tau_{c}$ & \multicolumn{1}{c}{ Description of cracking behaviour } \\
\hline$\pi / 2$ & 0 & $>0$ & Only counter-clockwise dislocation without separation or crack \\
0 & $>0$ & 0 & Only separation or crack without dislocation \\
$-\pi / 2$ & 0 & $<0$ & Only clockwise dislocation without separation or crack \\
\hline
\end{tabular}

the two blocks on either side of the crack. As shown in figure 3, the relative movement consists of components of separation and dislocation that can be determined based on the relative displacement of points $P$ and $Q$.

The new positions of $P$ and $Q$ are $P^{\prime}$ and $Q^{\prime}$, respectively, after cracking. When $P$ is superimposed with $P^{\prime}$, the relative displacement vectors for all other points are shown in figure $3 \mathrm{c}$. Vector $\overrightarrow{Q Q^{\prime}}$ represents the relative displacement of the two blocks on either side of the crack. Vector analyses of $\overrightarrow{Q Q^{\prime}}$ result in angle $\varphi$ between $\overrightarrow{Q Q^{\prime}}$ and $\overrightarrow{P Q}$. Hence, the relative separation, $w_{c}$, or cracking width along $\overline{P Q}$ and relative dislocation, $\tau_{c}$, can be calculated using the following equations, respectively:

$$
\begin{gathered}
w_{c}=\left|\overrightarrow{Q Q^{\prime}}\right| \cos \varphi, \\
\tau_{c}=\left|\overrightarrow{Q Q^{\prime}}\right| \sin \varphi .
\end{gathered}
$$

Equation (6) shows that angle $\varphi$ is significant only if its value is between $\pm^{\pi} / 2$ because theoretically when cracking occurs, the blocks are separating from each other. Based on Equation (7), a positive $\varphi$ indicates counter-clockwise movement for the separating blocks whereas a negative $\varphi$ indicates clockwise movement. Table 1 lists the three extreme cracking behaviours as represented by three special $\varphi$ values:

\section{Experimental}

The three-point loading experiment will be used for conducting laboratory work to study the feasibility of the DIC method proposed in this research.

\subsection{Experimental equipment and methods}

The experimental equipment consists of (i) an MTS-1000KN-40GPM hydraulic control system (photo 1) equipped with MTS-407 controller (photo 2), and (ii) Test Frame consisting of 3D vertical test machine (photo 1), and digital camera (CANON-EOS300D). Table 2 lists the specifications of these equipments.

3.1a Loading method: The three-point loading device has a span of $1300 \mathrm{~mm}$ as shown in figure 4. The loading procedures are as follows. (i) The process is controlled using displacement control; (ii) the specimen is pre-loaded with $0.3 \mathrm{kN}$; (iii) during the elastic loading stage, the loading is recorded each time when it is applied by pressing the hydraulic jack by $1 \mathrm{~mm}$ stepwise; (iv) digital images are taken; (v) the cracking position is marked in red; and (vi) when 


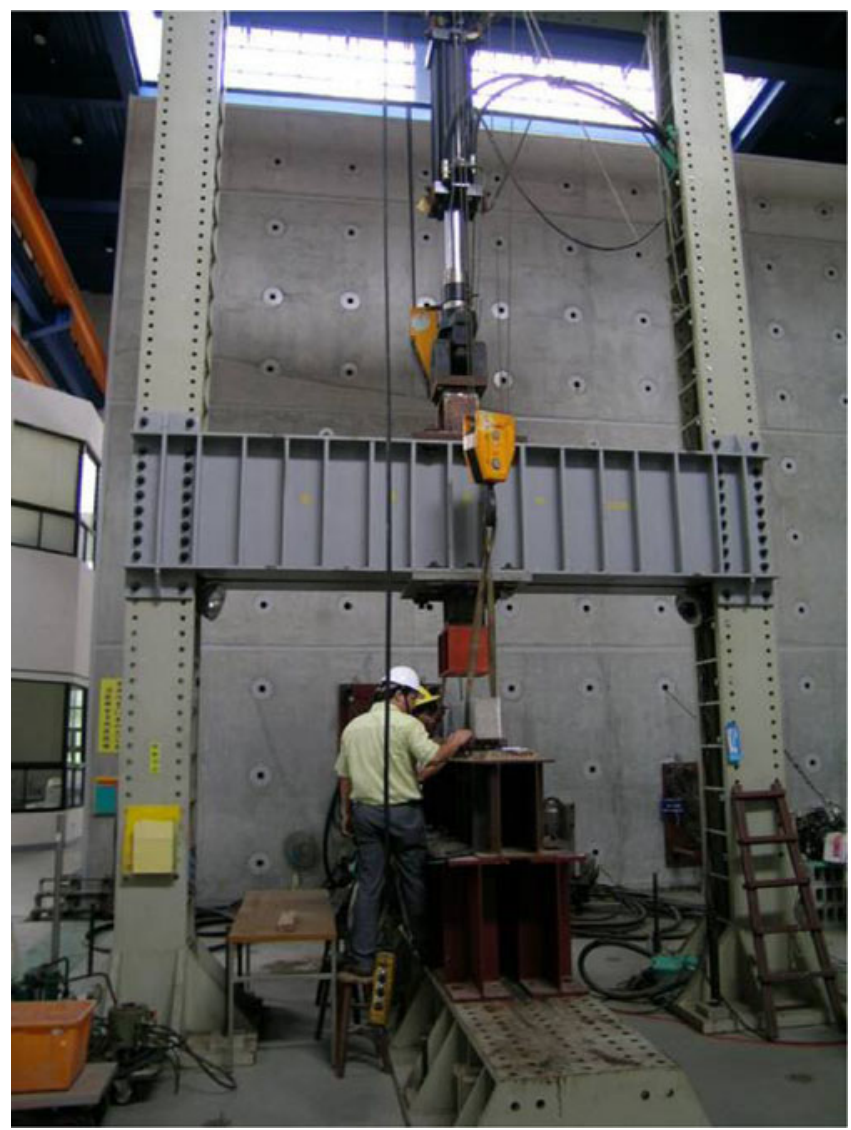

Photo 1. 3-D Experimental frame and oil-pressure activator.

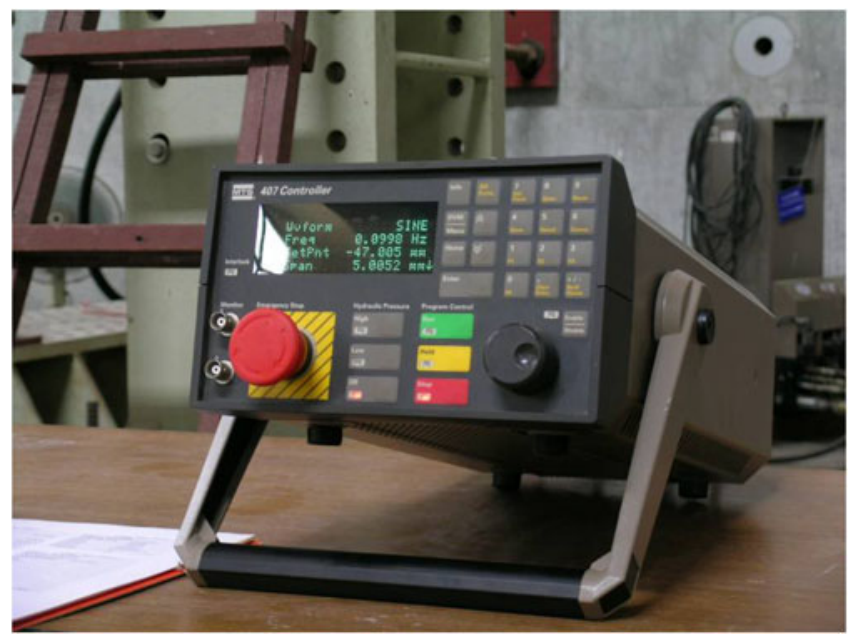

Photo 2. MTS-407 controller. 
Table 2. Camera parameters.

\begin{tabular}{lc}
\hline Width & 3072 pixels \\
Height & 2048 pixels \\
Horizontal resolution & $180 \mathrm{dpi}$ \\
Vertical resolution & $180 \mathrm{dpi}$ \\
Pixel depth & $24 \mathrm{bits}$ \\
Manufacturer & Canon \\
Model & Canon EOS 300D DIGITAL \\
Colour display & sRGB \\
Shutter speed & $1 / 2 \mathrm{~s}$ \\
Aperture & F/8 \\
Iris aperture & w/o flash \\
Focal length & $22 \mathrm{~mm}$ \\
Focal ratio & F/8 \\
Exposure time & $1 / 2 \mathrm{~s}$ \\
ISO speed & ISO-100 \\
Exposure compensation & 0 \\
\hline
\end{tabular}

the loading is in the plastic state as seen by reduced stress increasing rate, the hydraulic jack is pressed by $2 \mathrm{~mm}$ downward until the specimen ruptures.

\subsection{Experimental specimen}

The experimental specimen consists of two $150 \times 250 \times 1500(\mathrm{~B} \times \mathrm{H} \times \mathrm{L})$ reinforced concrete beam specimens with a $52.5 \mathrm{~mm}$ by $1 \mathrm{~cm}$ laid in the middle as an artificial crevice (figures 5 and 6 . The rebar reinforcement and concrete strength for these two types of specimen are described as follows:

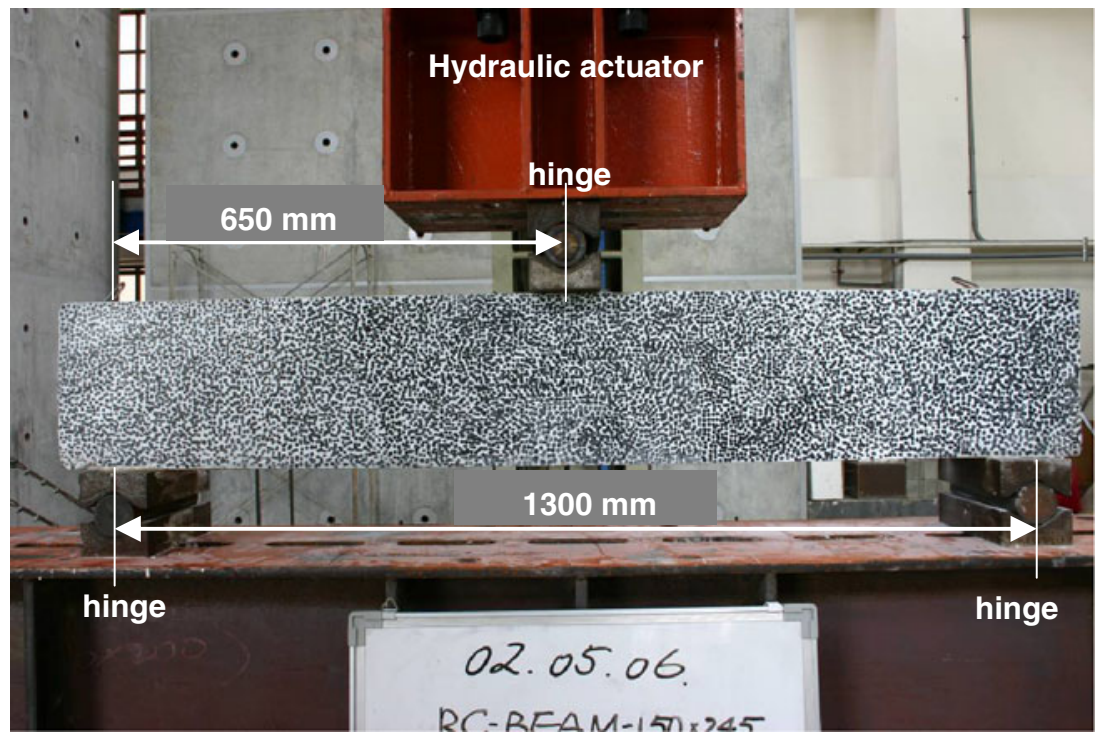

Figure 4. Simple three-point loading set-up. 


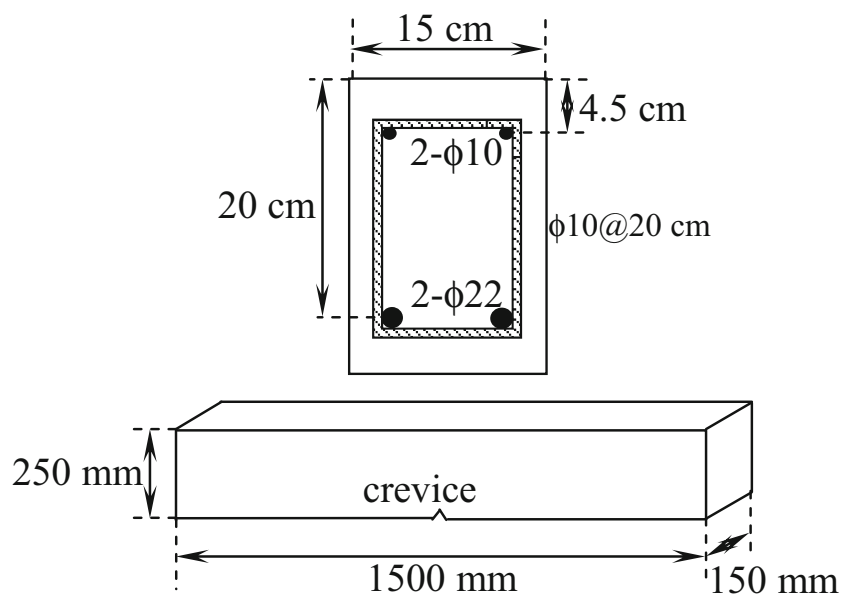

Figure 5. Specimen dimensions of specimen \#1.

3.2a Specimen \#1: Tension bar $\phi 22$; compression bar - $\phi 10$; lateral reinforcement bar $\phi 10 @ 20 \mathrm{~cm} 90^{\circ}$ bend (figure 5). Thickness of tension bar protection layer: $38 \mathrm{~mm} / 46 \mathrm{~mm}$. Cement strength: $23.91 \mathrm{~N} / \mathrm{mm}^{2}$. Bar yield strength: $370.86 \mathrm{~N} / \mathrm{mm}^{2}$; Bar tensile strength: $598.24 \mathrm{~N} / \mathrm{mm}^{2}$.

3.2b Specimen \#2: Tension bar: 2- $\phi 16$; compression bar: $2-\phi 10$; lateral reinforcement bar: \#3@20 cm, $90^{\circ}$ bend (figure 6). Thickness of the tension bar protection layer: $38 \mathrm{~mm} / 46 \mathrm{~mm}$. Cement strength: $27.06 \mathrm{~N} / \mathrm{mm}^{2}$. Bar yield strength: $511.93 \mathrm{~N} / \mathrm{mm}^{2}$; Bar tensile strength: $704.615 \mathrm{~N} / \mathrm{mm}^{2}$.
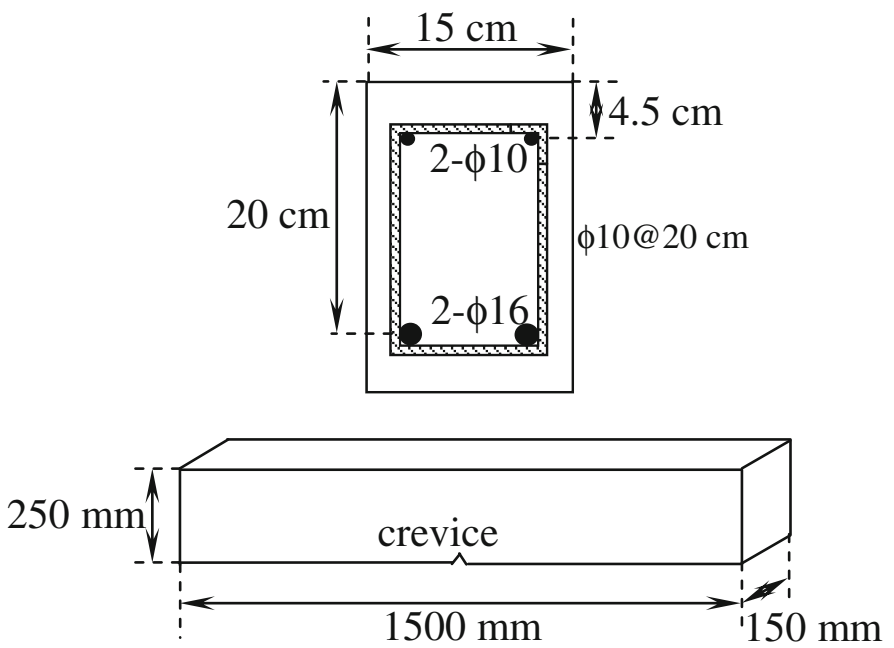

Figure 6. Specimen dimensions of specimen \#2. 


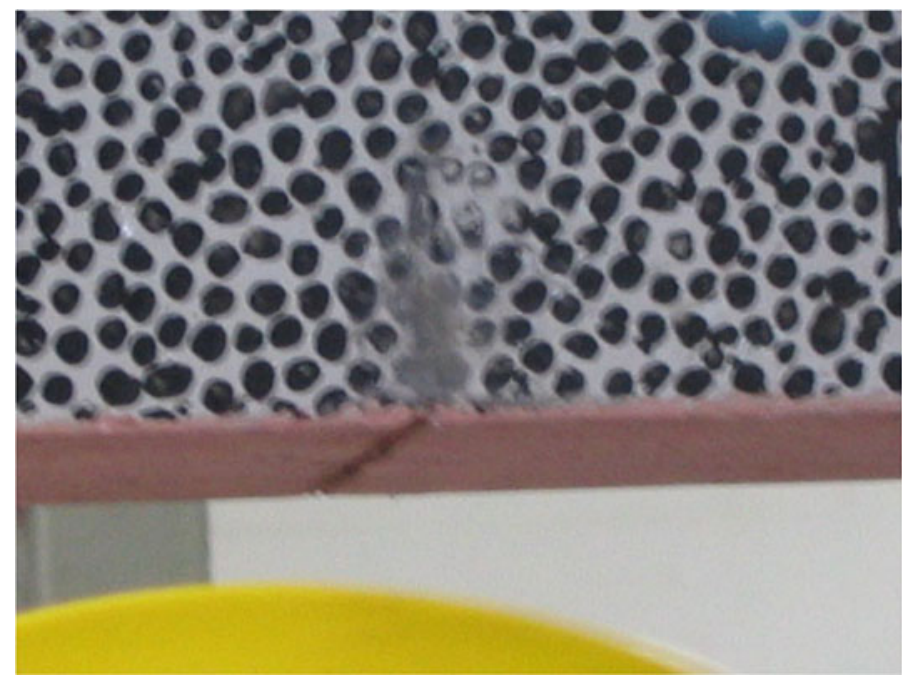

Figure 7. The specimen with pre-laid defective notch and marked speckles.

\subsection{Treatment of specimen surface}

The presence of identifiable natural stripe on the specimen surface is of great importance to the DIC method using digital images. If the specimen does not have natural stripes on the surface for identification, artificial stripes must be marked on the specimen surface. The procedures for marking artificial stripes are as follows:

(i) Surface Treatment: The weathered portion of the specimen surface is cleaned with coarse sand paper and wiped with a clean rag.

(ii) Prime: The easterly side of the specimen is primed with banana oil and then painted with white flat enamel.

(iii) Speckle: Speckles of $5 \mathrm{~mm}$ Dia. with irregular locations are evenly marked using black flat pain or black white-board pen. The ratio of overall black and white colour of the whole surface is 1:1. The pre-laid defective notch and pre-painted speckles are shown in figure 7.

\section{Results and discussion}

\subsection{DIC and visual analyses (specimen \#1)}

4.1a The displacement diagram: The grid displacements from digital images are converted into the actual displacement of the reinforcement beam specimen by $0.517 \mathrm{~mm} /$ pixel. The colour variation caused the displacement of $\mathrm{x}$-direction in figure 8 shows that the upper right corner and the lower left corner have negative values. This observation confirms to the variation of the real specimen when it is under loadings as shown in figure 9. When the loading reaches $85 \mathrm{kN}$ (figure 10), the bottom of the angular displacement diagram shows an obvious dividing line. There is 4 to 5 pixel (approximate $0.0026 \mathrm{~mm}$ ) difference between either side of the line that indicates minor squeezing, pressuring and twisting. When the loading further increases to $130 \mathrm{kN}$ (figure 11), the specimen digital image shows the occurrence of minor cracking on the surface 


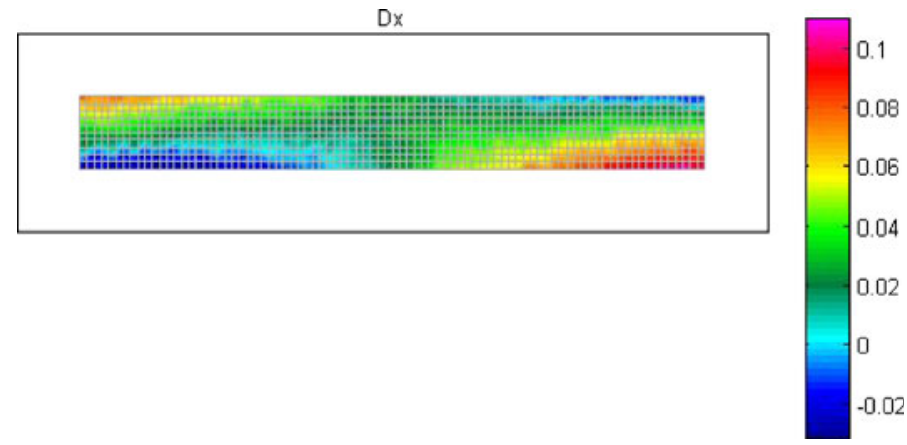

Figure 8. Displacement diagram (specimen \#1) for $8.2 \mathrm{kN}$ loading.

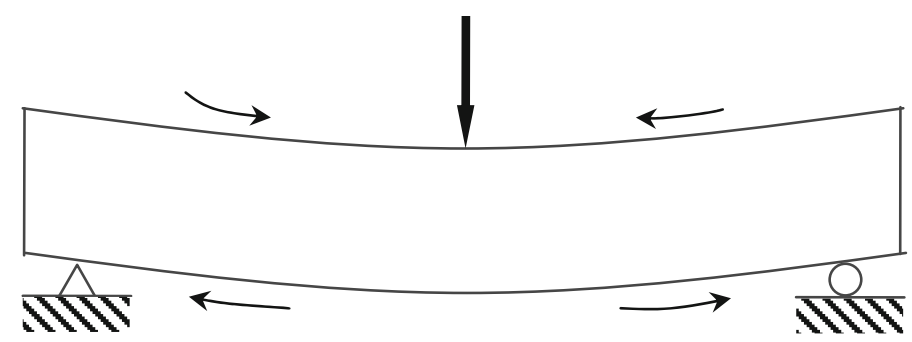

Figure 9. Schematic diagram of specimen deformation.
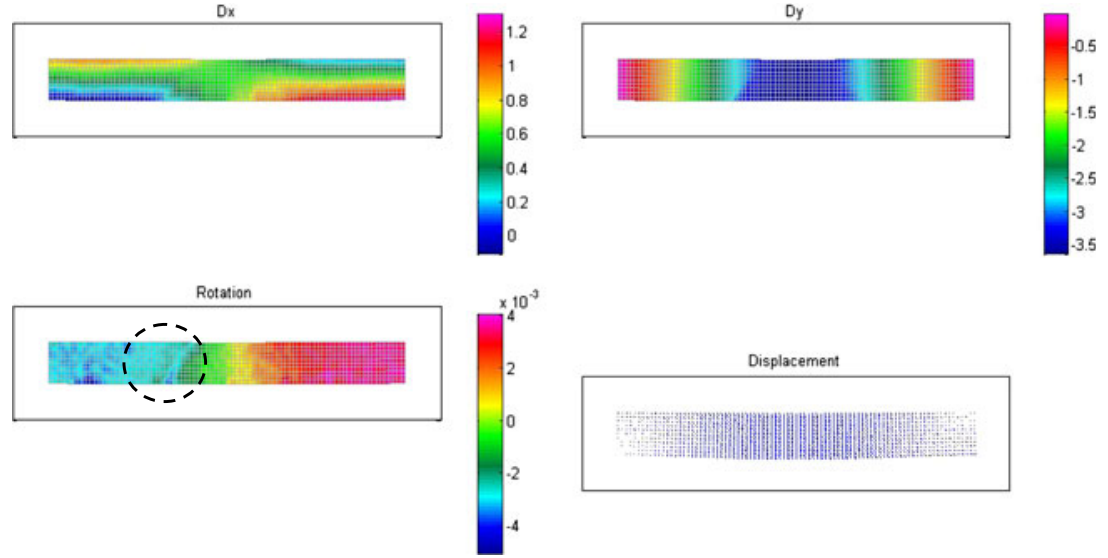

Figure 10. Displacement diagram for specimen \#1 subject to $85 \mathrm{kN}$.

(figure 12). However, the angular displacement on the displacement diagram as obtained using the DIC method clearly shows the process of cracking extension and the angular degree. Additionally, the diagram also reveals that the cracking has penetrated the test specimen. When the specimen is subject to $158 \mathrm{kN}$ loading, it is ruptured as shown in figure 13, and the position of rupture is same as the possible rupture position marked earlier during the stage of loading (figure 14). 

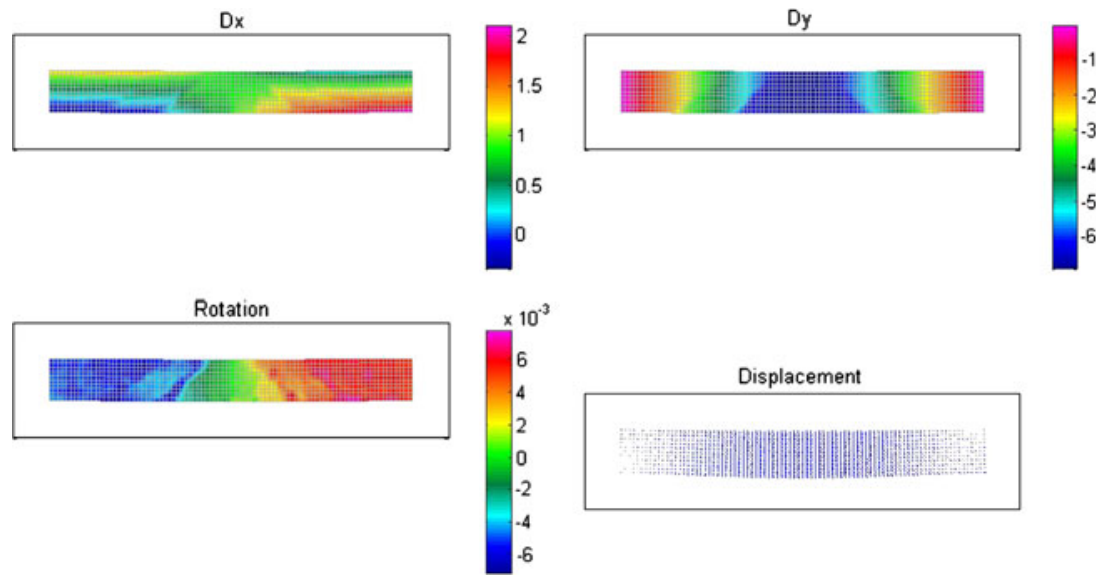

Figure 11. Displacement diagram for specimen \#1 subject to $130 \mathrm{kN}$ (with minor cracking on the surface of specimen).
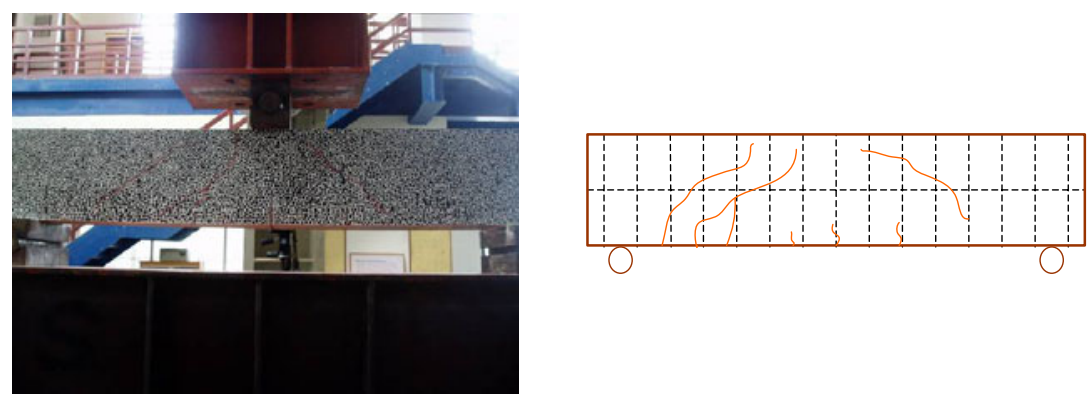

Figure 12. Distribution of cracking on the specimen subject to $130 \mathrm{kN}$ loading.
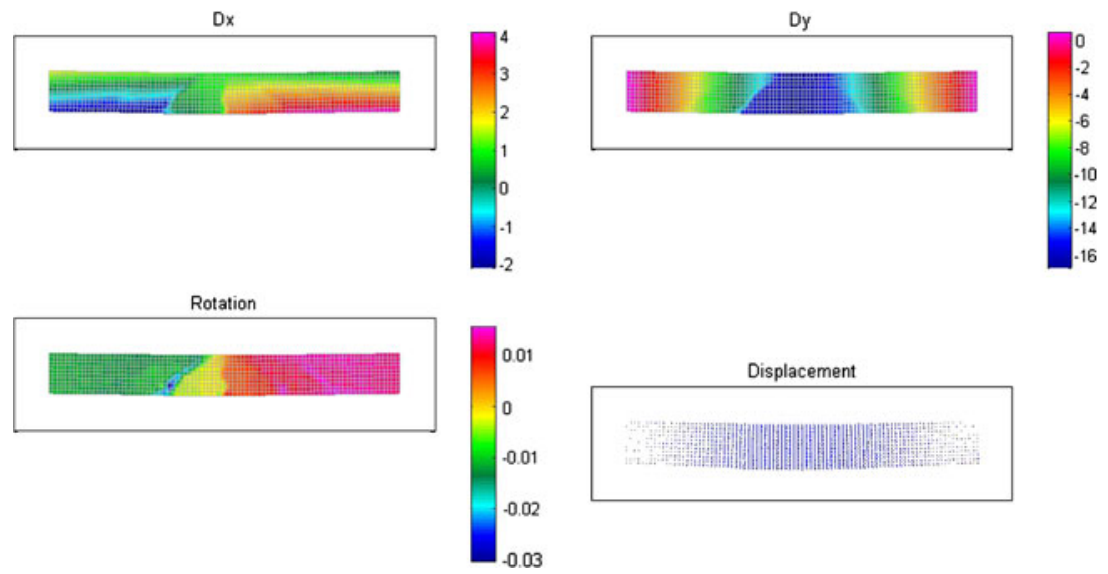

Figure 13. Displacement diagram (specimen \#1) for $158 \mathrm{kN}$ (with relaxed bonding strength). 

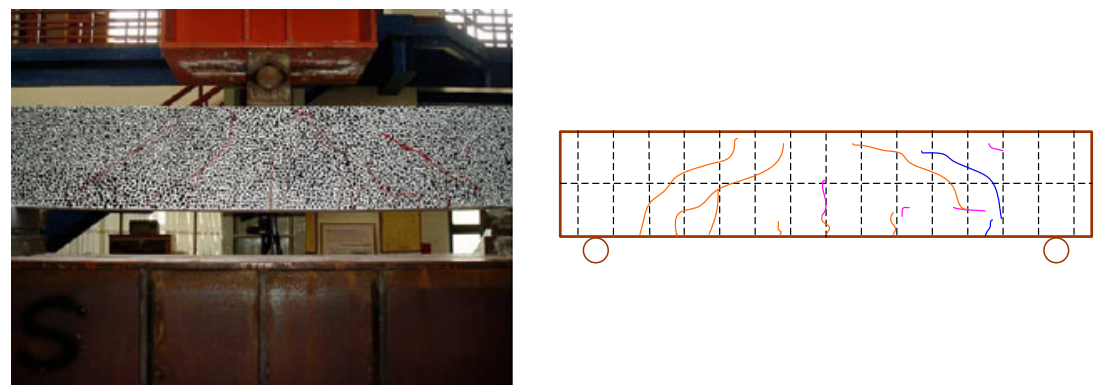

Figure 14. Distribution of cracking on the specimen under $158 \mathrm{kN}$.

4.1b Strain diagram: Figure 15 shows that all strains are evenly distributed indicating that when $8.2 \mathrm{kN}$ is applied, the crack has not been developed in the specimen. When $85 \mathrm{kN}$ is applied, the strain diagram shows minor strain concentration at the beam bottom in the $\mathrm{x}$ direction; the specimen strain is approximate $0.001 \mathrm{~mm}$ that has not reached the level to be considered as cracking. However, the strain diagram shown in figure $16(85 \mathrm{kN})$ reveals three positions of strain concentration below the x-direction but not in the y-direction. This indicates that the lower portion of the specimen has only x-direction cracking without vertical displacement. When the loading is increased to $130 \mathrm{kN}$ (figure 17), the string concentration shown on the von Mises strain diagram becomes more obvious. The difference between the two sides reaches 0.005 that can be considered to confirm the occurrence of cracks at the point of strain concentration. When viewing the image as shown in figure 12 with naked eyes, only very fine cracking can be observed. Figure 18 shows that the strain concentration for specimen subject to $158 \mathrm{kN}$ loading occurs at the same position roughly as for specimen subject to smaller loadings, and that the strain concentration penetrates the whole specimen. The strain diagram reveals $45^{\circ}$ direction for all strain concentrations that agrees with the digital image shown in figure 14 so that the specimen rupture is caused by shearing based on the strain diagram.
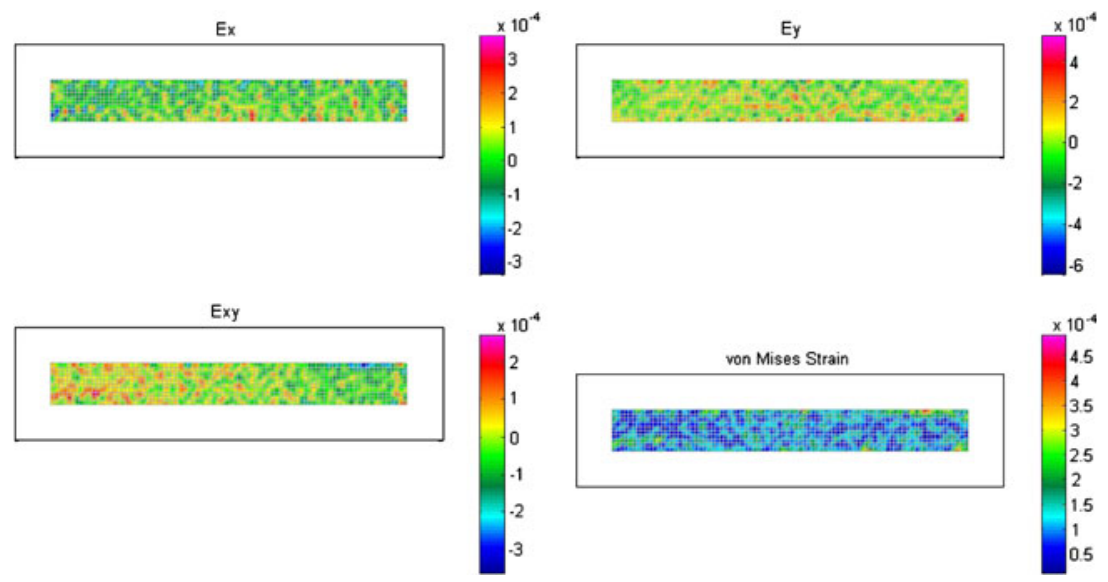

Figure 15. Strain diagrams for specimen \#1 subject to $8.2 \mathrm{kN}$. 


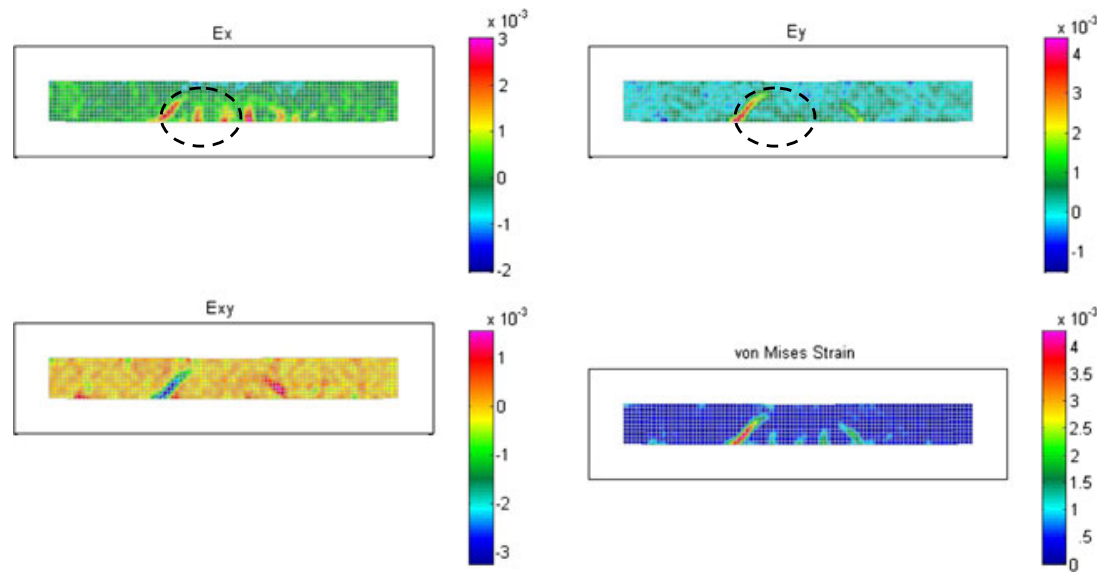

Figure 16. Strain diagrams for specimen $\# 1$ subject to $85 \mathrm{kN}$.

\subsection{DIC and visual analyses (specimen \#2)}

4.2a Displacement diagram: The displacement diagrams shown in figures 19-21 reveal no obvious changes in the y-direction displacement; this indicates the superior toughness developed in the steel bar so that the bar moves downward slowly in the y-direction. Both diagrams of $\mathrm{x}$-direction displacement and angular displacement show that the rupture of specimen starts from the pre-laid defective notch without the $45^{\circ}$ displacement, and hence, this is not failure in shear. From figure 19 (for $11.5 \mathrm{kN}$ ) to figure 21 (for $120 \mathrm{kN}$ ), the displacement reaches $18 \mathrm{~mm}$ occurring at the same position as the unusual displacement shown in the diagram of $\mathrm{x}$-displacement. This concludes that the mode of rupture for specimen \# 2 is controlled by open tension fissure.

4.2b Strain diagram: The phenomenon of strain concentration is not seen in figure 22. However, when the loading is increased to $107 \mathrm{kN}$ (figure 23), strain concentration occurs in the

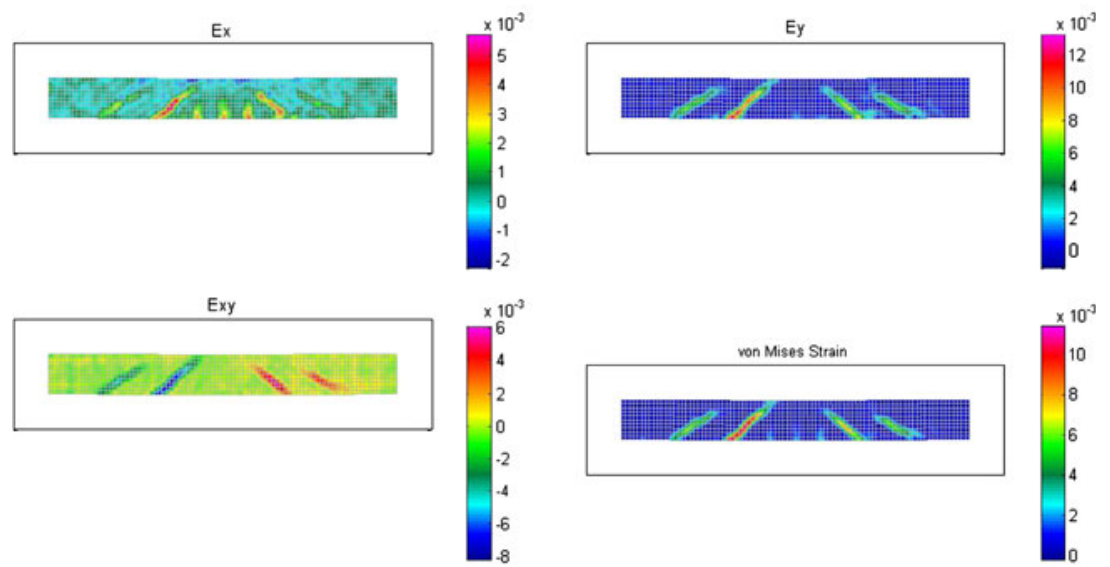

Figure 17. Strain diagrams for specimen $\# 1$ subject to $130 \mathrm{kN}$. 

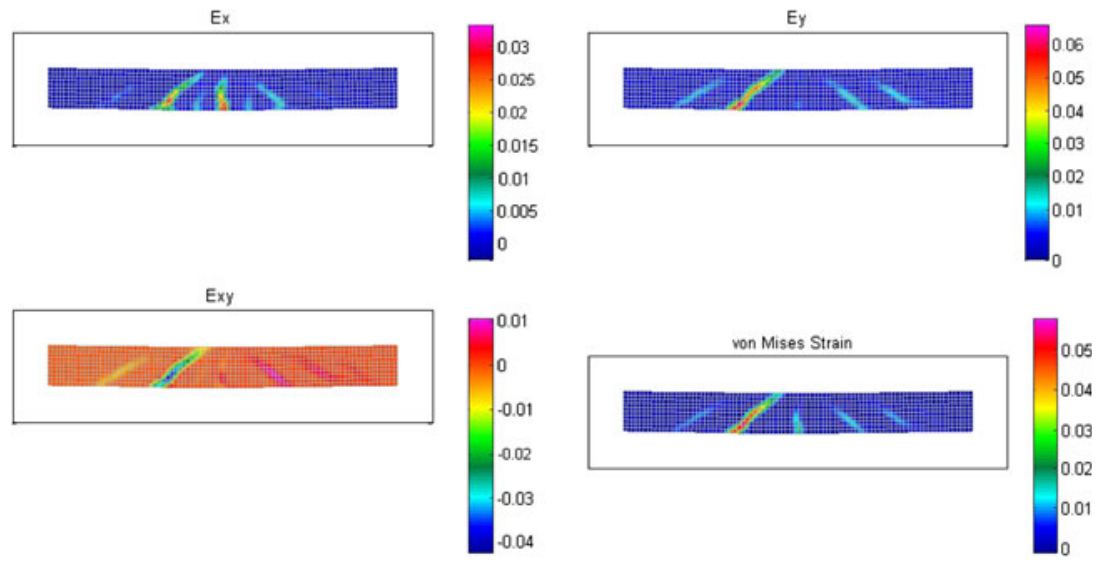

Figure 18. Strain diagrams for specimen \#1 subject to $158 \mathrm{kN}$ (with relaxed bonding strength).
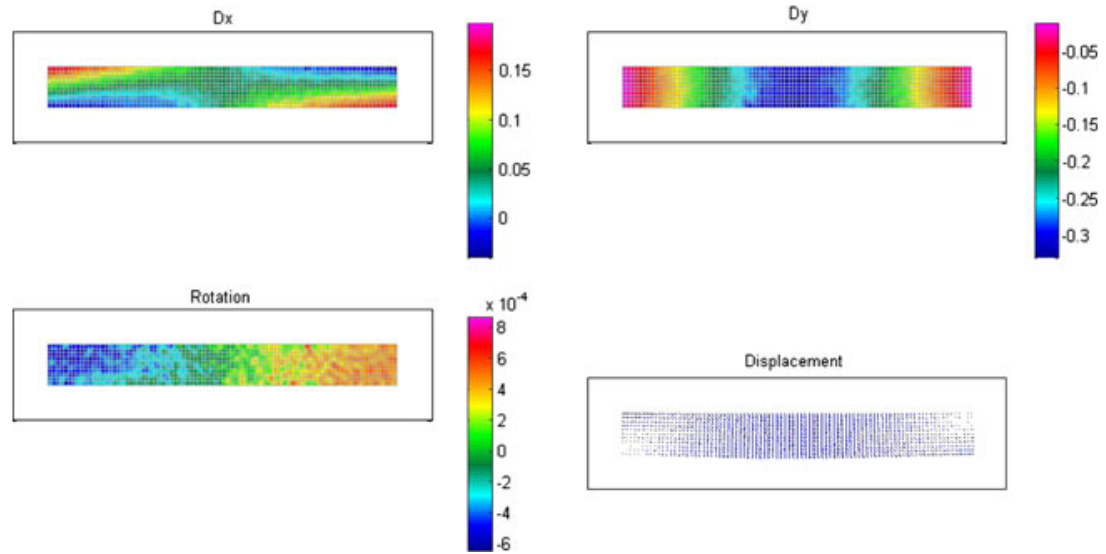

Figure 19. Displacement diagram for specimen \#2 subject to $11.5 \mathrm{kN}$ loading.
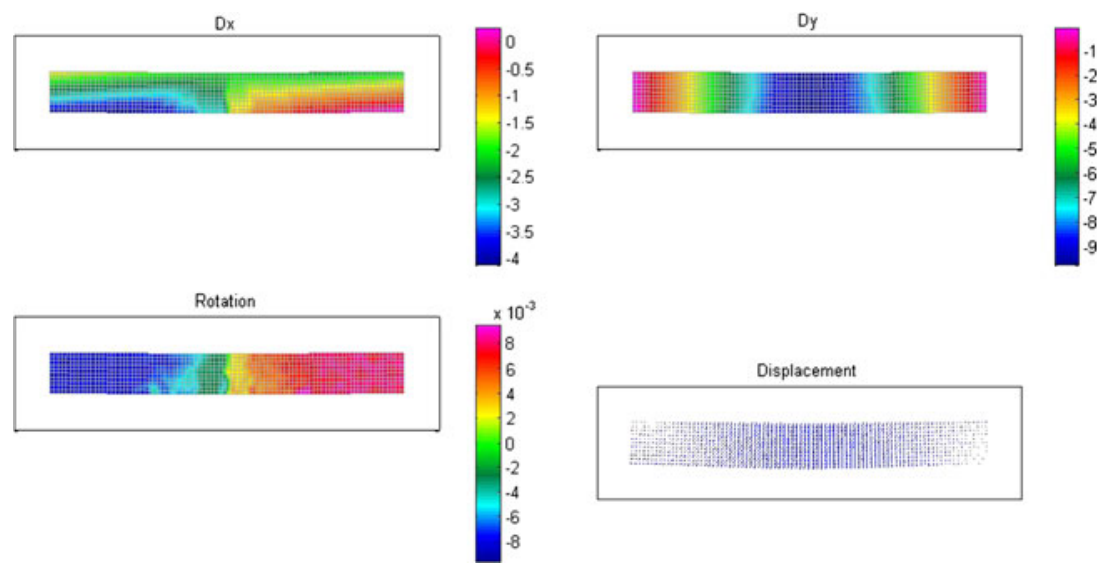

Figure 20. Displacement diagram for specimen \#2 subject to $107 \mathrm{kN}$ loading. 

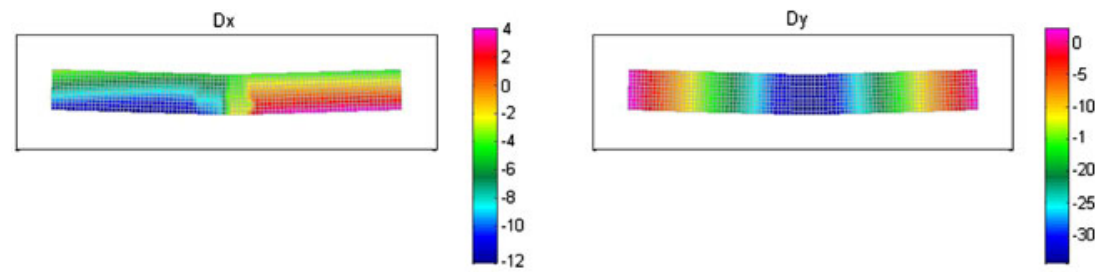

Rotation
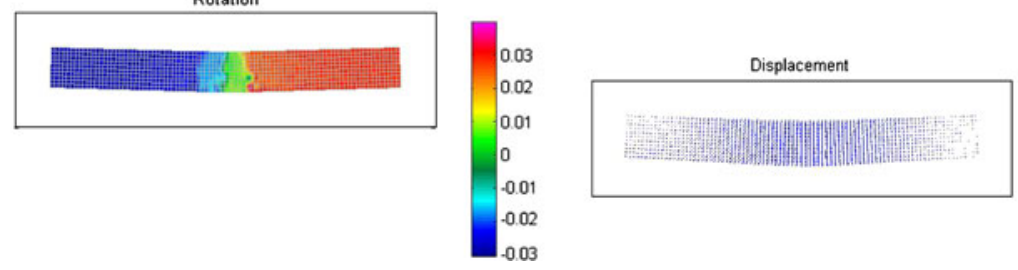

Figure 21. Displacement diagram for specimen $\# 2$ subject to $120 \mathrm{kN}$ loading.
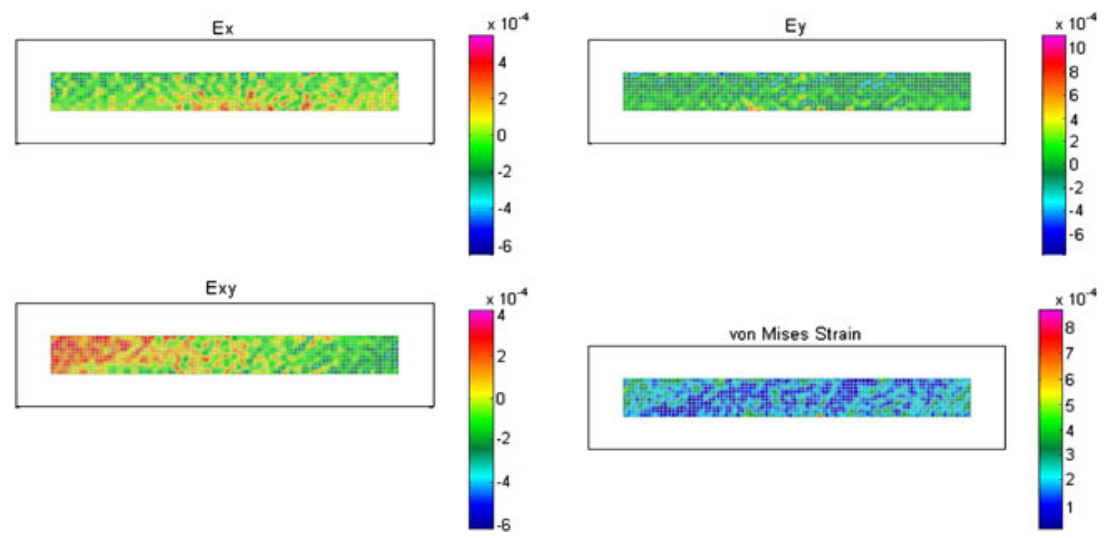

Figure 22. Strain diagram for specimen \# 2 subject to $11.5 \mathrm{kN}$ loading.
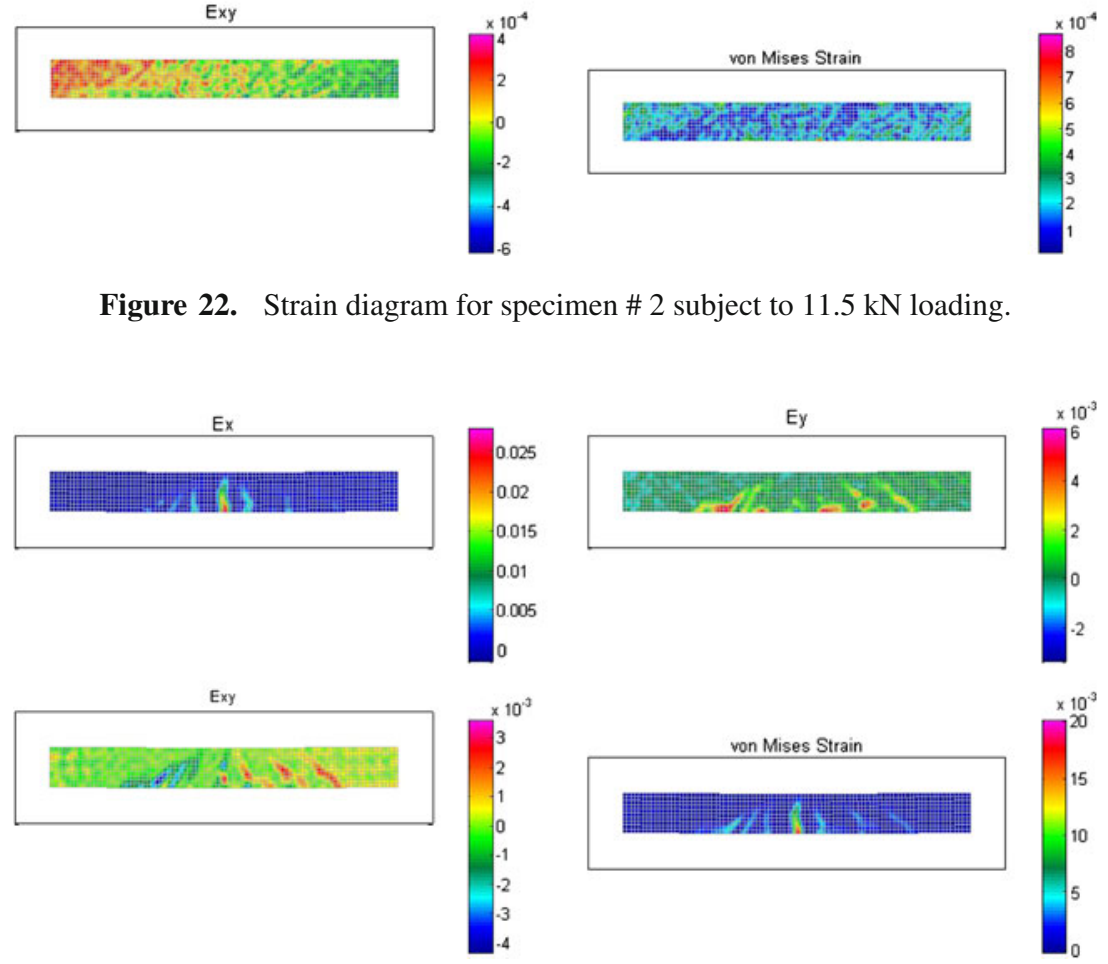

Figure 23. Strain diagram for specimen \# 2 subject to $107 \mathrm{kN}$ loading. 
middle of the beam bottom with several cracks seen in the specimen. Both figures 23 and 25 have similar locations where cracks occur; the y-direction strain diagram shows the tendency of slight but not very obvious phenomenon of $45^{\circ}$ strain concentration. When the loading reaches $120 \mathrm{kN}$ as shown in figure 25, the von Mises strain diagram shows the tendency of not obvious $45^{\circ}$ cracking. Hence, the occurrence of slight $45^{\circ}$ strain concentration in the y-direction can be deduced but cracks have not been developed in the specimen. Additionally, the strain diagram shown in figure 25 reveals that most cracks developed in specimen \#2 concentrate in the middle of the beam. The process and development of upward extension of strain can be revealed by comparing figure 26 with figure 24 . The comparison demonstrates that bonding strength has fully developed in longitudinal steel bars so that when the beam is subject to deflection, the strain concentration phenomenon is slowly extending upward allowing the steel bar to develop the yield strength effectively. The specimen rupture is dominated by flexural failure.

The phenomenon of strain concentration is not observed in figure 22 for specimen subject to $11.5 \mathrm{kN}$ loading. When the loading is increased to $107 \mathrm{kN}$ (figure 23), strain concentration obviously occurs at the center of the specimen bottom, and cracking develop in the specimen. The positions of cracking are similar to those shown in figure 24. Additionally, the y-direction strain concentration shows slight $45^{\circ}$ direction. When the loading reaches $120 \mathrm{kN}$ as shown in figure 25, the von Mises strain diagram does not show obvious $45^{\circ}$ direction of strain concentration. Hence, although a slight strain concentration occurs along the $45^{\circ}$, the phenomenon
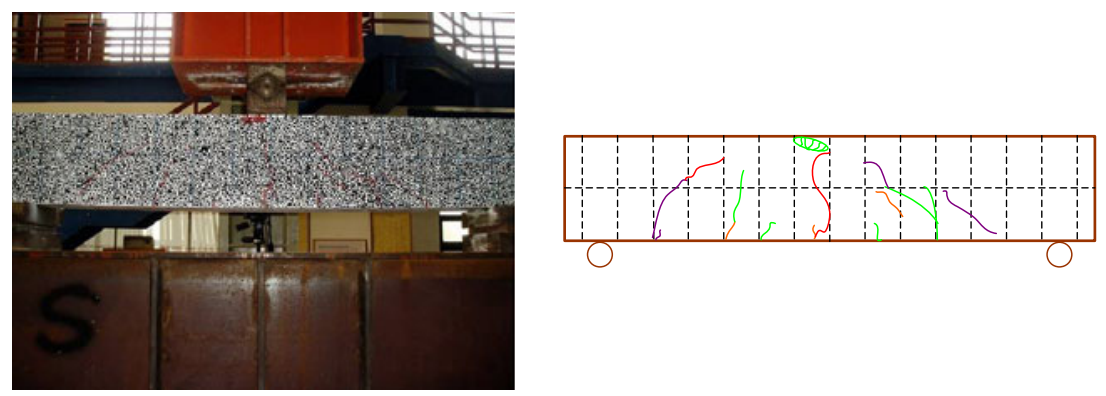

Figure 24. Strain diagram for specimen \# 2 subject to $107 \mathrm{kN}$ loading.
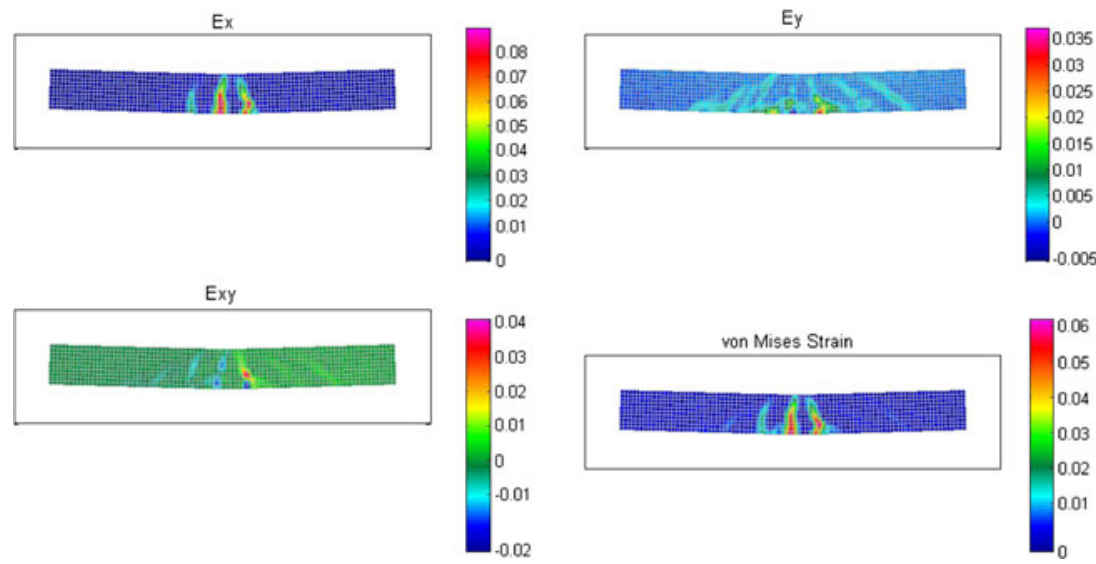

Figure 25. Strain diagram for specimen \# 2 subject to $120 \mathrm{kN}$ loading. 


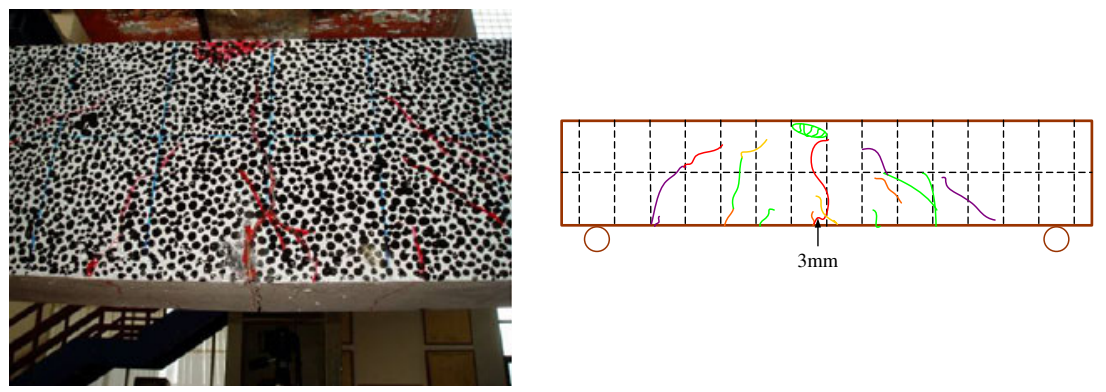

Figure 26. Distribution of cracks in specimen \# 2 subject to $120 \mathrm{kN}$ loading.

of cracking is not seen. The strain diagram shown in figure 25 indicates that most cracking positions on specimen \#2 concentrate in the middle of the beam that is similar to those shown in figure 26. Therefore, the strain diagrams show in figures 22, 23 and 25, the process of strain extending upward according to loading increase. The development of strain does not vary severely. The main reason of this phenomenon is that the longitudinal bars fully elaborate bond strength. Therefore, the strain concentration phenomenon slowly expands upward till specimen destruction. The specimen rupture is dominated by deflection rupture.

\section{Conclusions}

The DIC method can be used for observing the process of cracks development in reinforced beam, and measuring the uneven distribution of strain. Analyses of the displacement and strain fields lead to the following conclusions.

(i) The DIC method is capable of detecting and identifying early crack development, whereas the traditional method is incapable of doing so until the loading reaches a certain level that has already caused specimen cracking or rupturing.

(ii) Distinguishing the phenomena of strain concentration and cracking is based on integrating the field of strain distribution for various parallel and rotational displacements. Hence, the analyses proposed in this research for calculating the displacement field followed by converting the displacement field into strain field is capable of precisely recognizing the positions where strain concentration and cracks occur.

(iii) The failure mode for reinforcement concrete beam of various strength and steel bar reinforcement can be determined based on the displacement and strain diagrams.

(iv) The laboratory results presented in this research confirm that the proposed DIC method is applicable to the heterogeneous reinforcement concrete beam and to ensure the quality of this reinforced concrete beam.

\section{Acknowledgement}

This work has been supported by the National Science Council of Taiwan, ROC through grant no. NSC 98-2625-Z-327-005. This support is gratefully acknowledged. 


\section{References}

Bruck H A, McNeil S R, Sutton M A and Peters W H 1989 Digital image correlation using NewtonRaphson method of partial differential correction, Exp. Mech., 29: 261-267

Chen B and Liu J 2004 Experimental study on AE characteristics of three-point-bending concrete beams, Cement Concr. Res., 34: 391-397

Chu T C, Ranson W F, Sutton M A and Peters W H 1985 Application of digital-image-correlation techniques, Exp. Mech., 25(3): 232-244

Dost M, Vogel D, Winkler T, Vogel J, Erv R, Kieselstein E and Michel B 2003 How to detect Edgar Allan Poe's purloined letter-or cross correlation, algorithms in digitized video image for object identification, movement evaluation and deformation analysis, Proc. SPIE, 5048

Lu H and Cary P D 2000 Deformation measurements by digital image correlation: implementation of a second-order displacement gradient, Exp. Mech., 40(4): 393-400

Mendelson A 1983 Plasticity: Theory and Application. Malabar, Florida, USA: Krieger Publishing Company

Ozcan D M, Bayraktar A, Tahin A, Haktanir T and Tueker T 2009 Experimental and finite element analysis on the steel fiber-reinforced concrete (SFRC) beams ultimate behavior, Constr. Build. Mater, 23: 1064-1077

Ray S and Kishen J M C 2012 Fatigue crack growth due to overloads in plain concrete using scaling laws, Sadhana-Acad. Proc. Engi. Sci., 37(1): 107-124

$\mathrm{Ru}$ Z, Zhao H and Zhu C 2011 Crack propagation analysis of concrete beam subjected to three-point bending using XFEM, Appl. Mech. Mater., 94-96: 1655-1658

Shih M H, Tung S T, Tung and Sung W P 2008 Development of digital image correlation method to analyze crack variations of masonry wall, Sadhana Acad. Proc. Eng. Sci., 33(6): 767-779

Sutton M A, Turner J L, Bruck H A and Cjae T A 1991 Full-field representation of discretely sampled surface deformation for displacement and strain analysis, Exp. Mech., 31: 168-177

Swartz S E and Taha N M 1991 Crack propagation and fracture of plain concrete beams subjected to shear and compression, Struct. J., 88(2): 169-177

Vellinga W P and Onraet S 2000 Measurement of strain fields in the micron range, Proceedings of the Joint Meeting of the BVM and the NVvM 2000 in Papendal, Arnhem, 110-111

Vendroux G and Knauss W G 1998 Submicron deformation field measurements: Part 2. improved digital image correlation, Exp. Mech., 38(2): 86-92

Yehia N A B 2009 Fracture mechanics approach for flexural strengthening of reinforced concrete beams, Eng. Struct. 31: 404-416

Zhang J and Liu Q 2003 Determination of concrete fracture parameters from a three-point bending test, Tsinghua Sci. Technol., 8(6): 726-733 